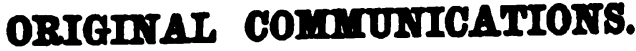

\section{NUMERICAL METHOD OF CONDUCTING MEDICAL INQUIRIES.}

\section{By THOMAS HODGKIN, M.D.}

[The following essay, which was read to the Physical Society of Guy's Hospital in the year 1834, may possibly with some advantage be reproduced at the present time. It will serve to exhibit the merits and uses of the numerical system, and also the mode in which it should be employed; and it may likewise call attention to what it is not, and to what it cannot effect, and thus counteract a cacoethes numerandi, or abuse of statistics, to which, as a statistician, I should object.

The hints to students at the close of the essay may be thought as suitable to those of the present day, as to those to whom they were addressed; and should they fall under the eyes of any of these, they may remind them of an old friend, whose repeated advice to the same purpose led to the formation of the Clinical Society of Guy's Hospital $\rightarrow$ a fact which the editors of the Guy's Hospital Reports have studiously suppressed.-T. H.]

IT was observed by Celsus that the art of medicine was conjectural; and, although since the time of that admirable writer very many important discoveries have been made in physiology and pathology, as well as in the kindred sciences, from which it might have been expected that the healing art would have been redeemed from the opprobrium to which it was subjected, it is to be feared that the stigma which his confession affixed to it is by no means removed. Nevertheless, there is no cause for the cultivators of the science of medicine to despair of their combined efforts raising it to a very different position amongst those sciences which are founded on observation. It has been remarked by Professor Louis, au author to whose labours I shall presently have to solicit your particular attention, that "the sciences bear the impress of the age in which they are cultivated. If this age is characterised by the spirit of inquiry, they do not, indeed, receive from it great éclat; but, what is much better, they make a real progress, by the acquisition of new facts, or the correction of those formerly erroneously observed. And if the spirit of inquiry is maintained for a considerable time, new facts every day more completely observed follow each other so quickly, that systems rapidly supersede one ancther." The truth of this observation of Professor Louis has been particularly apparent in the progress of medicine. The value of the most approved writers, whose works are unquestionably founded on the observation of nature, rather than in the wild speculations of their own imagination, have, notwithstanding their merit, lost much of their value in the lapse of time. It is not true, again to borrow the words of Professor Louis, "that facts. do not grow old". There are doubtless some well observed facts, which do not, and cannot, become impaired by time, because they have been well observed; but the immense majority of facts have grown old, and those which we may now collect will become aged in their turn, because they will bear to a greater or less degree the impress of the age, and of those methods of observation which, though more exact than those of former pcriods, are less rigorous than those which will be adopted hereafter.

If we look backwards to observe the progress which has been made in medical science, we find that in many respects it has been considerable; that diseases which were formerly obscure, are now much better understood; in proof of which I need only remind you of those affecting the viscera of the chest. Within my own recollection, it was thought a sufficiently minute diagnosis to set down a case as disease of the heart, without any reference to the kind of derangement, or the part of the heart affected; but we now with tolerable precision distinguish affections of one cavity from those of mother, the derangements of the substance of the heart from those of its valves, and in many cases can speak with tolerable certainty of the existence of pricurititis, which was formerly regarded, even by the grewent manters of diagnosis, as a most obscure affection. With respect to the lungs, again, what confusion was there between phthiois and other diseases implicating these organs, and attended with emaciation of the patient, until Ieennec had intraduced and cultivated the method of examining the chest by auscultation! If, however, we look forward, we shall see that our science is very far from having attained the limits to which it may reach. If we put the question to ourselves with a conscientious determination not to deceive ourselves in the answer, we shall find that there are very many points in pathology, physiology, and therapeutics, respecting which we cannot give positive answers, the result of absolute demonstration, but only such as are conjectural; and there is often abundant proof that these shrewd conjoctures are founded on insufficient data, since there is a great diversity in these conjectural conclusions, even in such as have been drawn by the masters of our art.

We cannot suppose that this state of our science is owing to deficiency in the talent which has been brought to its cultivation, but rather to the inherent difficulty of the subject. The field of observation is perhaps more extensive than is the case with any other science, and the elements are most numerous and complicated: hence there is a twofold difficulty; the one as respects the facts themselves, which require the utmost accuracy and perseverance for their collection, and which it is often difficult to define with precision; the other respecting the method by which the inferences are to be drawn from such numerous and complicated elements when collected. With respect to the collected facts, it must be admitted by all who are acquainted with this part of medical literature, that there exists a most lamentable deficiency; and that, whether we consider the narratives of cases which have terminated farourably or the reverse, we shall find that there are very few which can be admitted as the basis of rigorous deductions, either with reference to symptoms, pathological alterations, or modes of treatment. The principal causes of this have doubtless been, first, the very great labour and pains which it requires, first to make, and then to record, observations of the necessary minuteness; and secondly, that it almost always happens that, when a case is related, there is something present to the mind of the observer, which he can scarcely convey in words, but which the narrative which he has recorded will probably at a future time recall to his recollection. It is not until this process has been repeated several times, that the ideas, which probably presented themselves fecbly in the first instance, become sufficiently matured and defined to be susceptible of description by words. This explanation will, I conceive, sufficiently account for the scanty and doubtful inferences which can be drawn from many recorded cases.

I have stated that a part of the difficulty in the way of the cultivation of medicine, has proceeded from the defective method of drawing inferences from data afforded both by observation and experience. Too much has been left for that unassisted mental operation, which, in kind, resembles that to which I have alluded with reference to matters of observation; but which is manifestly misapplied to facts, which either are or may be recorded, especially when their number is very great. The state of the science of medicine, to which I have now alluded, has been observed and lamented by many who have devoted themselves to the study and cultivation of it. This has been most remarkably the case with Professor Louis, who has signalised himself by the zeal and indefatigable perseverance with which he has pursued his well directed inquiries, and by the success with which he has laboured to bring into notice a method of investigation and induction, which he has employed to a great extent, and with much adrantage-a method which is regarded by some as marking an era in the science of medicine, as the invention of fluxions has done for mathematics.

Professor Louis had already gone through the regular course of medical education. He had taken his degree, and had been for some jears engaged in the actual practice of 
hi profecsion, when doubts respecting many generally recoired medical opinions, and dissatisfaction with the mode in which these conclusions had been drawn, induced him to las aside practice, and derote his whole time and all his feculties, in the full vigour of the prime of life, to the most minute personal examination of disease, as it presented itealf under actual observation. With this view, he confined his attention to two large wards in a general hospital in Paris. The patients in these two wards were under the charge of one physician, Dr. Chomel. Louis made a minute and daily record of all the cases collected in those wards, taking care to find out and note every particular connected with the previous history of the patient, which could in any way affect or complicate the existing malady. When the cases terminated fatally, he was equally particular in recording all the appearances observed in the inspection of the body, not confining himself to those appearances which might be supposed to be connected with the last illness, nor even satisfying himself with the inference of the integrity of an organ by passing it over in silence, but taking care expressly to record the fact. These histories he afterwards subjected to a minute tabular analysis, taking care to bring together all those cases which belonged to a particular form of disease. These tables he subjected to a still further and more minute tabular analysis. By this purely statistical method, it is obvious that he aroided the danger of overlooking coincident circumstances, which, from being less striking, might fail to attract the attention which might have been arrested by others, far less general, or even accidental. Another advantage of this method was, that it precluded the possibility of being led astray by preconceived hypotheses, which he observes that he has in his own experience generally found to be erroneous and delusire. Some idea of the scrupulous anxiety which actuated Iouis in drawing his conclusions from these tables, may be formed from the fact that he has rejected all those cases which he recorded during the first six or eight months after he commenced this course of investigation, considering that his powers of observation and description were not sufficiently cultivated to furnish the elements of that severe and rigorous deduction which it was his object to make.

You will easily perceive that the method of Louis affords the most salutary check to those ardent and enthusiastic seniuses, whose fertile imaginations readily produce beautiful and captivating theories, which, when set off by brilliant language and vivid illustrations, and inculcated with equal zeal, have been ever apt to acquire an extensive but temporary influence on medical science, the legitimate progress of which they have most seriously impeded.

Such has been the basis of the analytical or numerical method, upon which Professor Louis has now been acting for about twelve years: but, to form an adequate idea of its value, we must consider the variety of questions connected with medical science, to which it is strictly applicable. It must be obvious that there are many points which admit of being submitted to numerical examination; as, for example, whether the male or female sex is the more subject to a particular affection. The medical man who is attending a large number of both sexes, may be said to have a fair opportunity of settling this question; but, if he have merely trusted to the impression which the cases made upon his mind as they occurred, it will be by no means improbable that the conclusion which he may draw may be erroneous, especially if the proportion does not greatly differ: if, however, he have taken care to register the cases as they occurred, and to sum them up at the end of the time devoted to the investigation, instead of saying that it was his impression that the one sex was rather more liable than the other, -an impression which might be erroneous, but which, if correct, would only convey an indefinite idea to the mind of another,-he would be able to give a definite idea in numerical proportion, which would be at once intelligible, and uninfluenced by any bias which accidental circumstances may have given to the mind of the observer. The only objections which could be urged, might be that the extent of the obeervations made was inrufficient, or that they had been made under circumstances favourable or unfarourable to the one or to the other sex; but the cases being numbered, the real value of the observer's opportunity would itself be defined; whereas, without this, it might be overrated by some, or undervalued by others. If, besides recording the sex of the individuals, the observer have taken care to notice the age, the previous habits, and the various other attendant circumstances of each patient, it will be possible to analyse the cases of each sex, so as to ascertain whether the obserrations have been made as to the influence of sex under circumstances equally farourable to each sex; and if under unequal circumstances, it might be ascertained where and to what extent this inequality had existed.

Let us suppose an inquiry of another kind; as, for example, whether the occurrence of a particular symptom in the course of a particular disease is to be regarded as influencing the prognosis favourably or unfavourably, or neither. The observer who trusts to transient impressions of the cases as they occur, will be very liable to be biassed by the striking character of some particular cases which have fallen under his notice, and his conclusions may in consequence either be exaggerated or erroneous; but if the observer have taken the number of his cases, and noted the occurrence of the symptom in question, and the event of the cases with respect to speedy or late recovery, or to death, he will be enabled to state in a definite manner how the occurrence of the symptom in question has stood with respect to each event.

It is needless that I should multiply illustrations, as I trust you are prepared to subscribe to the following remark of Louis: "Whether we wish to appreciate the value of symptoms, to know the progress and duration of diseases, to assign their degree of gravity, their relative frequency, the intluence of medical constitutions upon their development, to enlighten ourselves as to the value of therapeutical agents, or the causes of diseases, it is indispensable to count". But, before we can begin to count, we must have the data to be counted ; and if we attempt toapply this method to the mass of observed cases already recorded, we shall find abundant proof of that deficiency of which I have already complained this evening. Besides the omission of rarious points which might be stated, either positively or negatively, considerable difficulty in the analysis of reported cases arises from the use of terms which, though they may be intelligible to the reporter himself, are indefinite to him who hears or reads them. This is particularly the case with those epithets which admit of degree; as, when we say the skin is hot, this is only a relative quality, and an indefinite idea is conveyed by the expression. The use of a thermometer would fix its meaning, and allow a strict comparison to be made with the temperature of another person, or with that of the same person at another time. This difficulty is often felt with respect to the description of the condition of organs subjected to examination after death; as, for example, when it is said the heart is large or small, these are necessarily vague expressions, which will convey different ideas to different individuals. It must be confessed that some of these difficulties are almost inseparable franu the subjects of inquiry: and the instance which I have last mentioned may be takeu as an illustration of this remark, since a heart of a certain size and weight may be large with respect to one subject, and small with respect to another; nor would it greatly assist to compare the weight of the heart with that of the body, seeing that the amount of fat and muscle bear so uncertain a proportion to the general dimensions of the individual, that the weight of the body may give an erroneous idea of the scale on which the individual is formed. In such cases, a more correct estimate might be formed by instituting a numerical comparison between the various organs in the same body; and, in doing this, we should very legitimately bring the inquiry within the range of the numerical method.

A very good idea of the principles which actuated Iouis, and of the advantages to which he looks forward from the adoption of the numerical or analytical method, may be 
found in an essay which he wrote on clinical instruction, when he was a candidate for the professor's chair. A translation of it has recently been published, with the sanction of the author, by my accomplished friend Peter Martin, of Reigate; and I strongly recommend it to the attentive perus of those especially who are now occupied in the clinical wards of this hospital.

You may perhaps be disposed to ask what this laborious method, in the hands of so able an observer, has been able to effect in the course of twelve years? In the first place, he has collected an enormous pile of well obserred and detailed cases, so arranged that the corresponding circumstances are to be found in similar columns, under particular heads, constituting a mass of data to which he can have recourse for a distinct and numerical representation of the frequency or rarity of any particular fact within the range of his past observation. You will at once perceive that it must still be a labour of considerable time to make the further analysis of these cases. Yet, when I had the pleasure of paying the professor a visit, rather more than a year ago, he showed me a large collection of these analyses, some of which had already been employed as the means of extracting or deducing those conclusions, which he has given to the public in his works on Phthisis, on Typhus Fever, Pericarditis, and some other subjects; whilst others furmish the materials of conclusions which he has yet to publish.

Amongst the conclusions at which he has arrived, I may mention the following as the most remarkable:-

That phthisis is most common in females, whilst pneumonia and catarrh have more unale subjects; a fact opposed to the idea of the inflammatory origin of phthisis. That tubercles rarely, if ever, exist in any other part of the body, without also existing in the lungs, and generally to a greater extent in these organs. That chronic ulceration of the larynx and trachea, except it be venereal, is almost invariably the consequence of phthisis. That typhus fever, within the extensive limits of his observation, has been only found in conjunction with disease of the aggregate glands of the small intestines; and that it rarely, if ever, attacks those above fifty, or under fourteen years of age. 'That pericarditis, though esteemed a rare and fatal malady, attacks about one person in twenty-two, and is mostly followed by convalescence.

Some of these conclusions could scarcely have been guessed at, without the application of a statistical or nugurical method; others, which I might mention, I am persuaded might have been noticed and stated with confidence, after careful observation in an extensive field, without the employment of such a method. For example, I had myself observed and publicly noticed the fact, that emphysema of the lungs was a condition which seemed adverse to the occurrence of pleuritis, as well as to the production of some appearances common in lungs not so affected. The impression was strong on my own mind, though I had not sought the numerical expression of the fact; and my opinion might have been fairly called in question. Louis, I am since informed, has drawn the same conclusion by numerical analysis, and made the fact indisputable, at least within the range of his observation. Some conclusions, instead of being anticipated, may even be decidedly opposed by the conclusions which others have drawn; thus, with respect to fat liver, which Louis has stated, with the sanction of his counted cases, to be a derangement of structure, occurring in a large proportion of phthisical patients, whilst it is seen in a very small proportion of other patients, my conclusions with regard to the same affection would be decidedly different. I became acquainted with the characters of this derangement in Paris; and, when I had long sought for it in vain in this country, I could not suppose that I overlooked it. Yet, in the course of that time, I had examined many bodies of patients, carried off by phthisis in various forms. It is only in such an absolutely negative statement as this, that the numerical deductions of Louis can be opposed by others not obtained in the same rigorous manner; and even here the numerical conclusion must remain unahseen. It is only limited in its applieation; and this very discrepancy furnishes a matter of further inquiry, in which the numerical method may lead to a solution.

Though the almost infinite labour of the numerical method, and the time which it requires before the observer can feel warranted in advancing his deductions, may easily account for $s 0$ few works, besides those of Iouis himself, having yet appeared on the basis of the numerical system, there are two authors who have adopted it, whose names I cannot omit to mention. The one is Dr. Lombard, of Genera, who has followed up a numerical investigation of the same disease (phthisis pulmonalis) with which Louis has himself employed it. The work of Dr. Lombard is justly esteemed one of great merit and value, and is deservedly apnealed to as classical authority. The second is that of the late Dr. Jackson, jun., of Boston, on the malignant cholera, as it prevailed epidemically in Paris in 1832. This work, though the production of a young man who still regarded himself as a student, may be justly esteemed as a masterpiece of its kind. I beliere it to be the most complete and perfect specimen of the application of the numerical system. The tables which I lay before you as illustrations of the method, are copied from that work. Dr. Jackson, during his visit to Europe, applied himself with the most persevering zeal to acquire whatever was to be learnt in our profession, in the different schools which he visited; but it was to the instructions and practice of Professor Louis that he principally devoted himself. He returned to his native city, Boston, with every advantage which practised observation and cultivated tact could supply, to pursue his inquiries upon the numerical system into the diseases of his own country. Whilst pursuing this inquiry, with ardour and industry which justified the highest expectations of his friends, he became the subject of fever, to which his exertions exposed him, and was cut off by a premature death, which has inflicted a severe and serious loss, not only upon his relatives and friends, but upon his country and his profession.

"Nox atra caput tristi circumrolat umbrá. Hen miserande puer!

Manibus date lilia plenis.

Purpureos spargam flores, animamque amici His saltem adcumulem donis, et fungar inani Munere."

The application of the numerical method to inquiries connected with the science of medicine, which has been so ably practised and successfully inculcated by Professor Louis that he may justly be regarded as its principal advocate, is not, however, altogether new or singular in his hands. The principle is distinctly announced and recom. mended by Cabannis. It is minutely detailed in the Book of Analysis, by Dr. T. J. Todd, which, however, has been written, not only since Louis commenced his labour, but since he has published some of his works, though the idea does not seem to have been borrowed from Louis. The plan has even been acted upon, although, it must be confessed, only in an imperfect and partial manner. All our tables of mortality, so essential to life assurances and annuities, are founded on this kind of inquiry. The comparative prevalee of different diseases has been sought in the same manner, but with data the most unworthy of confidence; which, in fact, afford no hope of accuracy, except in the balance of errors. In Dr. Young's work on medical literature, an inference favourable to the result of medical practice is drawn from a comparison of the event of disease, when early brought under medical treatment, and when this has been neglected. The comparison is stated numerically, and is sufficient to show that the principle of the system of which I have been speaking was approved by that philosophical physician. During the alarming and fatal visitations of cholera, by which so many cities of Europe have been quickly deprived of a large portion of their inhabitants, the numerical system, as it were by a common feeling, was almost unirersally had recourse to. Who is there, whether of the medical profession or out of it, who there, whether of the medical profi indifferent to the evi-

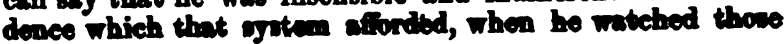


which stated numerically the daily increase of victins, and the proportion of seirures to recoreries?

An adminable application of the numerical method to phyciology is soen in Dr. Edwards's researches concerning the influence of physical agents upon life, where many of the points of inquiry rest upon degrees of difference in which uniformity cannot be expected, and to which answers on only be drawn from arerages accurately derived from an adoquate number of well observed cases. The subjects enentially connected with pathology and therapeutics, in which the assistance of the numerical system is required, are precisely analogous to the physiological questions to which I have last alluded. When I was at Bologna, in 1824, Professor Tommasini was fully impressed with the importance of examining all the organs and tissues, under every affection, and spoke to me of a plan which he had formed for carrying this inquiry into effect, by the combination of the exertions of the students attending that large medical school. I have not heard whether he made any exertion in the execution of this design. Shortly after I undertook the care of the department of morbid anatomy in this hospital, I conceived the idea of making the observations which I collected subservient to an analytical inquiry of this kind, and commenced a tabular arrangement of the result of the inspections which I made; and this plan has been continued until I have at length attained a pile of cereral hundred cases so arranged, and from which I trust I may be able to extract some curious and perhaps unexpected conclusions: at the same time, I am very far from arrogantly supposing that my records approach to the value of those of Professor Louis, more especially with re. spect to the enumeration of symptoms which preceded death.

In referring to published inspections, I have often found cause to regret the omission of statements with respect to various parts, which, not being the seat of the principal lesion, are passed over without a word being said of them. Blank forms, designed to be filled up during the progress of an inspection, have been contrived and printed by my friend W. Cocks, which, if generally employed, would tend materially to obviate this evil in future, as well as greatly to facilitate the adoption of the numerical system.

The use of weights and measures, as well as of the scalpel, of the magnifying glass, and of some chemical reagents, would greatly contribute to increase the value of post mortem inspections, and furnish data to which the numerical method would be perfectly applicable.

There are some symptoms and facts which admit of being expressed, not merely in numbers, but in forms which speak to the eye. Thus, the range of the pulse and temperature may be represented by lines or curves similar to those employed by meteorologists to represent the rariations of the barometer and thermometer, the fall of rain, the amount of evaporation, etc. This plan was adopted thirteen or fourteen years ago, by the late Dr. Duncan, jun., for the adrentage of his clinical pupils.

From what I have already advanced, it must, I conceive, be erident that the numerical system, if employed with accuracy and the extent of observation which its principles require, and with the subsidiary aid which it admits, would do more to redeem medical science from the character of conjectural than any other method with which we are at present acquainted ; and great benefit would doubtless arise to the public from its beneficial influence upon practice. The routine practitioner-for there will doubtless ever be some of this description-will in his routine adhere to those modes of treatment which unquestionable experience has sanctioned, rather than to those which have been introduced by the spoculative models he may have followed, or which he might feel disposed to adopt under the influence of imposing suthorities; and the genius who might disdain these trammels, and seek by the efforts of his original mind to introduce improvements and extend the limits of his profemion both in knowledge and resources, will find, on the one hand, s check to the errors into which he may deriate in the trati which this aretem exposes to viow; and, on the other hand, when in the right, he would be able to draw from it proofs which the most imposing authority could not withstand.

A specimen of the futile efforts of such opposition to the inferences deduced by the employment of the numerical system may be seen in the attack made by Broussais on two of the works of Louis. The unquestionable talent and powerful sarcasm of the author of the Examen des Doctrines Médicales, under which many other systems and authors have seemed to gire way, the physiological views upon which he so arrogantly plumes himself, and the authority of his name and experience, make unitedly but a miserable figure when confronted with the counted facts of his accurate and statistical opponent.

But even the numerical system, with all its titles to out respect and favour, may be overrated; and when it is stated that this system is to place medicine on a level with the exact sciences, we must demur before we yield our assent. The calculations for which it furnishes the data are not like those by which the morements of the heavenly bodies are predicted; they have no reference to the laws by which the operations to which they are applied are regulated. With respect to the past, it is, indeed, an invaluable method of bringing into view facts which, without it, are not prosented for our inspection in a way in which they can be duly appreciated; but with respect to the future, it appears to me to be rather an application of the doctrine of probabilities : this, however, I do not advance as any objection to its application. Nor is it my object, in making the observation which I am next to offer, in any degree to disparage the system, but rather to offer a caution lest its advocates should be induced to reject or despise inquiries in which this method may not have been employed.

There are many cases which, when carefully observed and detailed, possess very considerable value even when they stand alone; there are points susceptible of actual demonstration without any great multiplication of cases; and there are inquiries which may be pursued perhaps more minutely and successfully by those whose attention is concentrated upon them, than by those whose powers of observation are expended in the wide search for erery possible symptom and morbid alteration of structure. The labours of such inquirers are very far from being opposed to those of the followers of the numerical system; in fact, they are rendering an essential service, since they tend to discover and direct attention to those points, which it would be the object of the employers of the numerical system to observe and record.

Although much might be added to what $I$ have said in praise of the method and labours of Professor Louis, you will readily conceive that it is impossible for the exertions of one man, whaterer be his opportunities, talents, and industry, to carry the scheme into perfect accomplishment, and to obtain results which may be admitted as unexceptionable general conclusions. This is the inevitable effect of local or other partial influences, which affect the results obtained from the data furnished by the observations of any single individual. I mention this, not by way of disparagement, but as holding out a powerfnl stimulus to others to co-operate in a work which admits of such an extensive and useful division of iabour. Already an association has been established by some zealous and well-informed young medical men from various quarters and countries, who met in the medical school at Paris for the purpose of collecting and combining observations made upon the plan which $I$ have described. Labour of this kind will necessarily take up a considerable portion of time; it can therefore be undertaken by those only who are engaged in the pursuit of their studies, or who have not entered deeply into the allengrossing occupations of private practice. I wish I could induce the gentlemen who seek to complete their medical studies in this hospital, by attending to the practice of our physicians, to combine for a purpose of this kind. Although their commencing efforts, like those of louis when he began, might want the unquestionable and rigorous fidelity or completeness of detail, which would be required to entitle 
then to bo placed on lasting record amonget thowe narretire from which statistical results of an unquestionable chingcter mas be deduced, jet, by combination and mutual sivion, histories of this description would not be 80 diffcilt to produce as jou may imagine.

In the meantime, every individual heartily ongaged in In undertaking would derive incalculable benefit from this application of his powers, and the advantage would be falt bJ himself and his patients throughout tho whole of his medical career.

I have been induced to bring forward to the Physical Society the exposition of the method and advantages of the numerical system which I have just offered, from an earnest colicitude that the rising generation of medical men in this country may not be backward in contributing their quota towards the substantial advancement of medical science, and that the students of this hospital in particular may be first and foremost in thus vindicating the honour of the medical profession in England, and of the medical schools in this city. I have long been forcilly impressed not only by my own experience, but by what I have had frequent opportunity of observing to be the case with others, that there is no position so advantageous to the medical student as the post of clinical clerk. The number who can obtain this post is necessarily small and limited, but if you will act upon the hint which I have thrown out, all the gentlemen, however numerous, who may be following the medical practice of the hospital may participate in the advantages of that post. I would earnestly recommend them so to distribute themselves, that a certain number might be attached to the practice of each physician, precisely as the dressers are to the surgeons. By this arrangement a good collection of well authenticated cases might be made, and numerous important but unlooked for results would in all probability be brought into view.

\section{TWIN PREGNANCY : RUPTURE OF UTERUS : RECOVERY.}

\section{By A. H. PATERSON, Esq:}

Os September 10th, 1853, at half-past five, P.M., I was called to see an Irish woman, E. Mullins, aged 35, living in a miserable room in this town. She had been in her fourth labour twenty hours. She previously had had bad times, and had once borne twins. Two children, I believe, had been born alive. After her last confinement, she had a severe attack of peritonitis, followed by abscess near the umbilicus. She had now reached the full time. The patient, on my arrival, looked fatigued, but not pinched or ghastly. The abdomen was very prominent and pendulent, the vagina cool, and the os uteri dilated. The brim of the pelvis did not appear contracted. The liquor amnii had escaped the night before. She had strong bearing down pains, the midwife assured me, till very shortly before my visit: she lay down, sat up, and occasionally walked about, though with difficulty. On making an examination, the head was discovered presenting naturally, but receded on being touched. There was very trifling pain, and no uterine contraction. I ordered two halfarachm doses of powdered ergot. This rather increased the pain, but was soon returned by vomiting, which had also previously occurred during the day. She now complained of much abdominal tenderness, particularly towards the right iliac fossa.

10 P.x. There was little change. I attempted to deliver with the forceps, but could not grasp the head, which receded before the blades, and did not allow of their passing enficiently over it; so that, on making traction, they alipped. The motion of the child's head caused great pain, recembling cramp. I now repeated the ergot without reet.

Bept. 11th. 1 A.x. The patient felt easy; she took trents drope of laudanum, and dozed for sereral hours. Butreen tro and three, A.M., I left her.

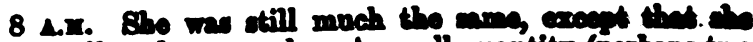

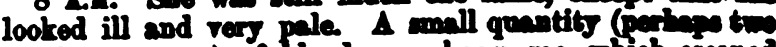
or three ounces) of blood was shown me, which cocend after applying the forceps. I now gare chloroform, terind and with some dificulty remored s fine full-grown dax infant. I introduced my hand, and found the placents detached, and another infent and a large coil of intentine in the flaccid uterus. Mr. Broadbent, of this torm, now joined me, and assisted in the turning and delivery of the socond infant. On making an examination, he discorered two large rents extending across the enterior part of the body of the uterus, from the 0 towands the right side, and separated by 8 bend of the muscular tissue. During the removal of the second child, I placed my hand on the abdomen, and felt the head pass through the rent into the uterus. The pulse had up to this time been tolernbly full, and under a hundred. It now became feeble; and the woman was cold and faint. There was a very moderate discharge. The abdomen was carefully bendaged, and a drachm of leudanum given.

5 P.M. The extremities were rarm; the pulse 130. She had no pain, and had not slept. The opiate was ordered to be repeated at bedtime. The uterus was well contracted. The bladder was acting naturally.

Sept. 12th. 9 1.x. The abdomen was much distended with flatus. The patient had slept most of the night. Bhe had had a bad cough. The skin was warm and perspiring; there was occasional hiccough; the patient had not much pain; the abdominal tenderness was confined to the right side. She got out of bed in the course of the day, and stood up ; and lost several ounces of blood both at that time and afterwards. The pulse was 140. I ordered the following :-

\section{B. Etheris chlorici,} Tinct. opii, $\bar{a} \bar{a} \bar{a}$ pyx.

Sumantur quartâ quâque horâ.

Sept. 13th. The pulse was 130. She had had a bad night. The abdomen was tympanitic, except in the right side, where it was dull, and felt hard. The bowels were open. The lochia were natural.

Sept. 14th. The pulse was 120; the bowels were relaxed; the tongue was white and moist; the spirits were good; and there was no hiccough or sickness. The mirture was omitted; and she was ordered to take a grain of opium every six hours.

Sept. 15th and 16th. She was better. I ordered her to have broth and port wine.

Oct. 5th. Since last report, the patient had continued very weak. She had suffered much from spasmodic cough, which gave her great pain in the abdomen; and had occasional diarrhcea. On the right side, just below the false ribs, was a large painful tumour, with deep-seated fluctuations. She had been half starved. I procured some more nourishing food, and ordered a poultice to the side.

Oct. 9th. A large tumour had, since the last report, formed midway between the umbilicus and pubes : it burat this day, and a large quantity of foetid pus escaped. I ordered quinine.

Oct. 13th. I lanced the large abscess below the false ribs. Upwards of a pint of foetid pus was expelled with violence. The cough and all other symptoms wero quickly relieved.

My patient now rapidly recorered, suffering only from great irregularity in the borels, and pain and fistulence after meals.

This woman was again delivered by me three weeks since. I with some difficulty turned a fine child, but could not get the head through the brim, the cervical vertebre giving way. I, however, applied the forceps, and dolivered. The woman has done well, except that she has again had a large abdominal abscess below the umbilicus.

Rexarks. In the first labour, I ought doubtlese to have delivered much carlier; but the ejmptoms for many hours did not appear to necessitate my interference; and it mas not till after the escape of the blood that I mopected what had pecurred. The rupture took place, I belterve, aberth 